\title{
Thrombus aspiration during primary percutaneous coronary intervention is associated with reduced myocardial edema, hemorrhage, microvascular obstruction and left ventricular remodeling
}

Mohammad I Zia*, Nilesh R Ghugre, Kim A Connelly, Subodh B Joshi, Bradley H Strauss, Eric A Cohen, Graham A Wright and Alexander J Dick

\begin{abstract}
Background: Thrombus aspiration (TA) has been shown to improve microvascular perfusion during primary percutaneous coronary intervention (PCI) for patients with ST-segment elevation myocardial infarction (STEMI). The objective of our study was to assess the relationship between TA and myocardial edema, myocardial hemorrhage, microvascular obstruction (MVO) and left ventricular remodeling in STEMI patients using cardiovascular magnetic resonance (CMR).
\end{abstract}

Methods: Sixty patients were enrolled post primary PCI and underwent CMR on a $1.5 \mathrm{~T}$ scanner at 48 hours and 6 months. Patients were retrospectively stratified into 2 groups: those that received TA (35 patients) versus that did not receive thrombus aspiration (NTA) (25 patients). Myocardial edema and myocardial hemorrhage were assessed by $\mathrm{T} 2$ and $\mathrm{T}^{*}$ quantification respectively. MVO was assessed via a contrast-enhanced T1-weighted inversion recovery gradient-echo sequence.

Results: At 48 hours, infarct segment T2 (NTA 57.9 ms vs. TA $52.1 \mathrm{~ms}, \mathrm{p}=0.022$ ) was lower in the TA group. Also, infarct segment T2* was higher in the TA group (NTA $29.3 \mathrm{~ms}$ vs. TA $37.8 \mathrm{~ms}, \mathrm{p}=0.007$ ). MVO incidence was lower in the TA group (NTA $88 \%$ vs. TA 54\%, $p=0.013$ ).

At 6 months, left ventricular end-diastolic volume index (NTA $91.9 \mathrm{ml} / \mathrm{m} 2 \mathrm{vs}$. TA $68.3 \mathrm{ml} / \mathrm{m} 2, p=0.013$ ) and left ventricular end systolic volume index (NTA $52.1 \mathrm{ml} / \mathrm{m} 2 \mathrm{vs}$. TA $32.4 \mathrm{ml} / \mathrm{m} 2, \mathrm{p}=0.008$ ) were lower and infarct segment systolic wall thickening was higher in the TA group (NTA 3.5\% vs. TA 74.8\%, $p=0.003$ ).

Conclusion: TA during primary $\mathrm{PCl}$ is associated with reduced myocardial edema, myocardial hemorrhage, left ventricular remodeling and incidence of MVO after STEMI.

Keywords: Thrombus aspiration, Cardiovascular magnetic resonance, Myocardial infarction

\section{Background}

Primary percutaneous coronary intervention (PCI) is the mainstay of treatment in patients with ST-segment elevation myocardial infarction (STEMI) [1]. Despite advances in primary PCI and medical therapy, the incidence of heart failure, re-infarction and death in these patients remains significant [2]. No-reflow is a common

\footnotetext{
* Correspondence: mo.zia@utoronto.ca

Division of Cardiology, Schulich Heart Centre, Sunnybrook Health Sciences Centre, University of Toronto, 2075 Bayview Avenue, Toronto, ON M4N 3 M5,
} Canada

(c) 2012 Zia et al; licensee BioMed Central Ltd. This is an Open Access article distributed under the terms of the Creative Commons Attribution License (http://creativecommons.org/licenses/by/2.0), which permits unrestricted use, distribution, and reproduction in any medium, provided the original work is properly cited. adverse event leading to worse clinical outcomes in patients with STEMI undergoing primary $\mathrm{PCI}$, with atherothrombotic embolization being one of the contributing mechanisms [3-6]. Thrombus aspiration (TA) can theoretically protect the microcirculation from distal embolization, however randomized clinical trials have resulted in conflicting results [4,7-21]. In the study by Kaltoft et al. [13], thrombectomy was associated with increased infarct size and did not improve ST-segment resolution. Conversely, other trials such as REMEDIA (Randomized Evaluation of the Effect of Mechanical 
Reduction of Distal Embolization by Thrombus-Aspiration in Primary and Rescue Angioplasty), DEAR-MI (Dethrombosis to Enhance Acute Reperfusion in Myocardial Infarction) and TAPAS (Thrombus Aspiration During Percutaneous Coronary Intervention in Acute Myocardial Infarction) showed that thrombectomy improved microvascular perfusion. However, the impact of TA on other parameters of microvascular injury such as myocardial edema and hemorrhage was not addressed in any of these trials.

Cardiovascular magnetic resonance (CMR) represents the gold-standard method in assessing myocardial edema, myocardial hemorrhage, left ventricular remodeling and microvascular obstruction (MVO) [22-24]. The purpose of this study was to evaluate the relationship between TA as adjunctive therapy in primary PCI for patients with STEMI, and myocardial edema, myocardial hemorrhage, left ventricular remodeling and MVO.

\section{Methods}

\section{Study population}

Sixty patients presenting to Sunnybrook Health Sciences Centre in Toronto, with STEMI between July 2009 and March 2011 were enrolled. The main inclusion criteria were patients that met the standard diagnostic criteria for STEMI [25]. All patients had undergone primary PCI as part of a regional program that triages patients with STEMI to our centre for early revascularization. Exclusion criteria included hemodynamic instability (defined as systolic blood pressure $<90 \mathrm{mmHg}$, use of inotropic agents or an intraortic balloon pump), significant arrhythmias, significant renal dysfunction (estimated glomerular filtration rate $<30 \mathrm{~mL} / \mathrm{min}$ ), and typical contraindications to CMR such as pacemakers and implantable cardioverter-defibrillators. We obtained written consent from all patients, and the study was approved by the ethics review board of Sunnybrook Health Sciences Centre.

\section{Primary $\mathrm{PCl}$ protocol}

All patients were pretreated prior to revascularization with aspirin $162 \mathrm{mg}$ and clopidogrel $600 \mathrm{mg}$. Choice of anticoagulant (intravenous heparin or bivalirudin) and optional use of glycoprotein IIb/IIIa inhibitor were left to operator discretion. TA was performed with an Export Medtronic device (Medtronic Inc., Minneapolis, Minnesota) and its use was also left to operator discretion. Factors influencing the use of TA included target vessel size, degree of thrombus burden, no reflow phenomenon and clinical instability. Subsequently patients received aspirin, clopidogrel, beta-blockers, angiotensinconverting enzyme inhibitors, angiotensin-receptor blockers and statins as per standard of care.

\section{Angiographic and electrocardiographic analysis}

Thrombolysis In Myocardial Infarction (TIMI) flow grade, myocardial blush grade and thrombus score were estimated visually using previously described methods by 2 experienced observers who were blinded to use of TA [26-28]. ST-segment resolution, defined as $\geq 70 \%$ reduction in the sum of the ST-segment elevation score between electrocardiograms obtained before primary PCI and immediately after the procedure, was also recorded [29].

\section{CMR acquisition protocol}

Each patient was imaged at 2 time points: within 48 hours and 6 months post STEMI. Studies were performed on a $1.5 \mathrm{~T}$ clinical scanner (Signa Twinspeed HDx, GE Healthcare, Waukesha, WI) with commercially available CMR software, electrocardiographic triggering, 8-channel receive coil and breath holds at end-expiration. After performing a localizer scan, short-axis cine CMR (10-12 slices) was performed with a balanced steadystate-free-precession sequence (FIESTA, GE Healthcare) with the following parameters: repetition time $=3.7 \mathrm{~ms}$ and echo time $=1.6 \mathrm{~ms}$, flip angle $=45^{\circ}$, slice thickness $=$ $8 \mathrm{~mm}$, acquisition matrix $=256 \times 192$, field of view $=35$ $\mathrm{cm}$, bandwidth $=125 \mathrm{kHz}, 20$ cardiac phases per slice.

Myocardial edema was assessed by $\mathrm{T} 2$ quantification using a previously validated free-breathing cardiac-gated spiral imaging sequence with T2 preparation [30,31], 810 contiguous slices from base to apex and the following typical parameters: echo times $=2.9,24.3,88.2,184.2$ ms, 12 spiral interleaves with 4096 points each $(16.4 \mathrm{~ms}$ duration), slice thickness $=6 \mathrm{~mm}$, bandwidth $=125$ $\mathrm{kHz}$. Myocardial hemorrhage was assessed by $\mathrm{T} 2 *$ quantification using a cardiac-gated spoiled gradient echo sequence with multiple echoes, 8-10 contiguous slices from base to apex, and the following typical parameters: 8 echoes (1.4-12.7 ms), repetition time $=14.6 \mathrm{~ms}$, flip angle $=30^{\circ}$, acquisition matrix $=128 \times 128,8$ viewsper-segment, slice thickness $=8 \mathrm{~mm}$, bandwidth $=100$ $\mathrm{kHz}$ [31]. All echoes for a single slice were acquired in a single breath hold. Finally, a breath-hold, contrastenhanced T1-weighted inversion recovery gradient-echo sequence was used to depict the presence, location, and extent of myocardial infarction and MVO using the following parameters: repetition time/echo time $=5.4 / 2.5$ ms, flip angle $=30^{\circ}, 8-10$ contiguous slices from base to apex, slice thickness $=8 \mathrm{~mm}$, acquisition matrix $=192$ $\times 128$, field of view $=35 \mathrm{~cm}$. The inversion time was manually adjusted to null signal from normal myocardium. Short axis images were obtained 10 minutes after intravenous administration of Gadolinium-diethylene triamine pentaacetic acid $(0.2 \mathrm{mmol} / \mathrm{kg}$; Gadovist, Bayer Healthcare, Wayne, NJ). 


\section{CMR image analysis}

All cine CMR images were analyzed using QMass ${ }^{\circledR}$ MR software (Medis, Netherlands), and the results were the consensus of a minimum of 2 experienced observers who were blinded to use of TA. Endocardial and epicardial borders were delineated on the end-diastolic and end-systolic phases of short-axis slices for quantification of left ventricular volumes, function, mass, and infarct segment systolic wall thickening. Measurements were indexed for body surface area. End-diastolic wall thickness was measured in the infarct segment as an indicator of myocardial edema in the acute phase and wall thinning in the chronic phase. Myocardial T2 and T2* maps were constructed by fitting signal intensities at each pixel with an exponential model for the given echo times. Hemorrhage was identified as an area of hypointensity on T2-weighted images within the infarcted segment. Infarct size was quantified in a contrast-enhanced T1-weighted image using the full-width-half-maximum technique as previously described [32] while MVO was identified as a region of hypoenhancement within the region of the hyperenhanced infarct, 10 minutes post contrast administration. Infarct size, hemorrhage, and MVO were expressed as a percentage of total myocardium. Data fitting for T2/T2* maps, infarct, hemorrhage and MVO size computation were performed with custom-written scripts developed in MATLAB ${ }^{\circledR}$ (The Mathworks, Natick, MA). MVO was also recorded as a binary variable of being present or absent, based on the contrast-enhanced images [33].

\section{Statistical analysis and endpoints}

The study population was divided into 2 groups: TA versus no thrombus aspiration (NTA). Primary study end points were the degree of myocardial edema (T2 and end-diastolic wall thickness measurements), myocardial hemorrhage ( $\mathrm{T} 2 *$ measurement) and occurrence of MVO at the first time point of within 48 hours post-STEMI. Secondary endpoints included the occurrence of final myocardial blush grade $\geq 2$, final TIMI flow $\geq 2$ on angiography, rate of ST-segment resolution post primary PCI, and parameters of left ventricular remodeling including left ventricular end diastolic volume index (LVEDI), left ventricular end systolic volume index (LVESI), left ventricular stroke volume index (LVSVI), left ventricular ejection fraction, and infarct segment systolic wall thickening at the final time point of 6 months post STEMI. Continuous data were expressed as mean $+/$ - standard deviation and analyzed by the Student $t$ test. Categorical variables were reported as frequencies and percentages and analyzed by the chi-square or Fisher exact test, as appropriate. All tests were 2-tailed, and statistical significance was accepted at $\mathrm{p}<0.05$.

\section{Results}

Baseline characteristics

Eighty-five patients with STEMI were screened, 25 patients were excluded and 60 patients were included in the study. Reasons for exclusion included severe renal insufficiency, claustrophobia, hemodynamic instability and presence of permanent pacemaker. Clinical characteristics of both the TA and NTA group are shown in Table 1 and appear to be well matched in both groups. No difference in symptom to balloon time or door to balloon time was observed between groups. Reasons for not using TA by the operators included minimal thrombus burden visualized on the coronary angiogram, small vessel size, or preserved distal flow throughout the procedure. Glycoprotein IIb/IIIa inhibitor use was similar in both groups (NTA 52\% vs. TA 62.9\%, p =0.514).

\section{Angiographic, periprocedural and electrocardiographic findings}

TA was associated with more frequent final myocardial blush grade $\geq 2$ (NTA $44 \%$ vs. TA $88.6 \%, p<0.01)$ and ST-segment resolution (NTA 40\% vs. TA 68.6\%, p = 0.036 ) post primary PCI (Table 2). Final TIMI flow $\geq 2$ was equivalent in both groups (NTA 96\% vs. TA 97.1\%, $\mathrm{p}=\mathrm{NS})$.

\section{CMR analysis}

The initial CMR scan was performed at a mean of 34.4 hours post primary PCI and the second scan at a mean of 243 days post primary PCI in the overall group. Table 3 shows the CMR outcomes for both time points.

Figure 1 demonstrates the myocardial T2 and T2* maps along with late gadolinium enhancement (LGE) images in short-axis views from representative patients in the NTA and TA groups at 48 hours. In this acute phase, both measures of myocardial edema, i.e. infarct segment T2 (NTA 57.9 ms vs. TA $52.1 \mathrm{~ms}, \mathrm{p}=0.022$ ) and infarct segment end-diastolic wall thickness (NTA $11.4 \mathrm{~mm}$ vs. TA $9.3 \mathrm{~mm}, \mathrm{p}<0.01$ ), were lower in the TA group (Table 3 ). Infarct segment $\mathrm{T} 2 *$ was higher, indicative of reduced myocardial hemorrhage, in the TA group (NTA $29.3 \mathrm{~ms}$ vs. TA $37.8 \mathrm{~ms}, \mathrm{p}=0.007$ ). MVO incidence was also lower in the TA group (NTA $88 \%$ vs. TA 54.3\%, p = 0.013).

Figure 2 demonstrates the LVEDVI and LVESVI measurements along with LGE images in short-axis views from patients in both treatment groups at 6 months. Baseline LVEDVI, LVESVI, LVSVI, infarct segment systolic wall thickening, and left ventricular ejection fraction measurements were similar in both treatment groups. At 6 months, LVEDVI (NTA $91.9 \mathrm{ml} / \mathrm{m} 2$ vs. TA $68.3 \mathrm{ml} / \mathrm{m} 2, \mathrm{p}=0.013$ ) and LVESVI (NTA $52.1 \mathrm{ml} / \mathrm{m} 2$ vs. TA $32.4 \mathrm{ml} / \mathrm{m} 2, \mathrm{p}=0.008)$ were lower in the TA 
Table 1 Baseline Clinical Characteristics of the Study Population

\begin{tabular}{lllll}
\hline & Total $(\mathbf{n}=\mathbf{6 0})$ & NTA $(\mathbf{n}=\mathbf{2 5})$ & TA $(\mathbf{n}=\mathbf{3 5})$ & $\mathbf{p ~ V a l u e ~}$ \\
\hline Age, yrs & $59.6 \pm 10.6$ & $60.0 \pm 7.3$ & $59.5 \pm 12.6$ & 0.741 \\
\hline Males (\%) & $53(88.3)$ & $21(84.0)$ & $32(91.4)$ & 0.273 \\
\hline Diabetes (\%) & $15(25.0)$ & $6(24.0)$ & $9(25.7)$ & 0.242 \\
\hline Hypertension (\%) & $27(45.0)$ & $12(48.0)$ & $15(42.9)$ & 0.312 \\
\hline Dyslipidemia (\%) & $15(25.0)$ & $7(28.0)$ & $8(22.9)$ & 0.414 \\
\hline Smoking (\%) & $17(28.3)$ & $8(32.0)$ & $9(25.7)$ & 0.372 \\
\hline Prior Myocardial Infarction (\%) & $2(3.3)$ & $1(4.0)$ & $1(2.9)$ & 0.718 \\
\hline Prior PCl (\%) & $4(6.7)$ & $1(4.0)$ & $3(8.6)$ & 0.384 \\
\hline Creatinine, umol/L & $82.1 \pm 23.0$ & $81.1 \pm 17.1$ & 0.743 \\
\hline Symptoms to balloon, minutes & $397 \pm 304$ & $402 \pm 268$ & $391 \pm 291$ & 0.831 \\
\hline Door to balloon, minutes & $83.5 \pm 51.2$ & $83.2 \pm 39.8$ & $83.9 \pm 59.8$ & 0.765 \\
\hline
\end{tabular}

Abbreviations. NTA no thrombus aspiration; PCI percutaneous coronary intervention; TA thrombus aspiration

group (Table 3). LVSVI (NTA $40.4 \mathrm{ml} / \mathrm{m} 2$ vs. TA 35.8 $\mathrm{ml} / \mathrm{m} 2, \mathrm{p}=0.30$ ) and left ventricular ejection fraction (NTA $46.8 \%$ vs. TA $53.8 \%, p=0.11$ ) were equivalent in both groups. Infarct segment systolic wall thickening (NTA $3.5 \%$ vs. TA $74.8 \%, p=0.003$ ) and end diastolic wall thickness (NTA $4 \mathrm{~mm}$ vs. TA $5.7 \mathrm{~mm}, \mathrm{p}=0.008$ ) were both greater in the TA group at 6 months.

\section{Discussion}

Our non-randomized study demonstrates that TA during primary $\mathrm{PCI}$ is associated with reduced myocardial edema, myocardial hemorrhage, infarct size, left ventricular remodeling, and MVO after STEMI. We postulate that TA results in less myocardial injury, evidenced by the reduced infarct size, which in turn is responsible for

Table 2 Peri-Procedural Characteristics and Outcomes of the Study Population

\begin{tabular}{|c|c|c|c|c|}
\hline & Total $(n=60)$ & NTA $(n=25)$ & TA $(n=35)$ & p Value \\
\hline \multicolumn{5}{|l|}{ Infarct artery (\%) } \\
\hline LAD & $26(43.3)$ & $12(48.0)$ & $14(40.0)$ & 0.344 \\
\hline LCx & $12(20.0)$ & $6(24.0)$ & $6(17.1)$ & 0.210 \\
\hline RCA & $22(36.7)$ & $9(36.0)$ & $13(37.1)$ & 0.416 \\
\hline Multivessel disease (\%) & $26(43.3)$ & $9(36.0)$ & $17(48.6)$ & 0.128 \\
\hline \multicolumn{5}{|l|}{ Thrombus score } \\
\hline 2 & $22(36.7)$ & $8(32.0)$ & $14(40.0)$ & 0.224 \\
\hline 3 & $23(38.3)$ & $11(44.0)$ & $12(34.3)$ & 0.419 \\
\hline 4 & $4(6.7)$ & $2(8.0)$ & $2(5.7)$ & 0.426 \\
\hline \multicolumn{5}{|l|}{ Adjunctive Pharmacologic Therapy } \\
\hline Glycoprotein IIb/Illa inhibitor (\%) & $35(58.3)$ & $13(52.0)$ & $22(62.9)$ & 0.514 \\
\hline Bivalirudin (\%) & $25(41.7)$ & $11(44.0)$ & $14(40.0)$ & 0.664 \\
\hline \multicolumn{5}{|l|}{ Stent type } \\
\hline Bare-metal & $41(68.3)$ & $16(64.0)$ & $25(71.4)$ & 0.517 \\
\hline Drug-eluting & $19(31.7)$ & $8(32.0)$ & $11(31.4)$ & 0.736 \\
\hline Mean peak creatine kinase peak (IU/L) & $2177 \pm 1579$ & $2321 \pm 1271$ & $2142 \pm 1643$ & 0.513 \\
\hline ST-segment resolution (\%) & $34(56.7)$ & $10(40.0)$ & $24(68.6)$ & 0.036 \\
\hline \multicolumn{5}{|l|}{ Post PCI TIMI flow grade (\%) } \\
\hline$>2$ & $58(96.7)$ & $24(96.0)$ & $34(97.1)$ & 0.987 \\
\hline \multicolumn{5}{|l|}{ Post PCI MBG (\%) } \\
\hline$>2$ & $42(70.0)$ & $11(44.0)$ & $3188.6)$ & 0.001 \\
\hline \multicolumn{5}{|l|}{ Mean PCl to CMR time } \\
\hline Scan 1, hours & $34.4 \pm 17.3$ & $36.6 \pm 16.2$ & $34.0 \pm 17.6$ & 0.435 \\
\hline Scan 2 , days & $243 \pm 62$ & $222 \pm 52$ & $247 \pm 69$ & 0.212 \\
\hline
\end{tabular}

Abbreviations. CMR cardiovascular magnetic resonance; $L A D$ left anterior descending; $L C x$ left circumflex; $M B G$ myocardial blush grade; $R C A$ right coronary artery; TIMI Thrombolysis in Myocardial Infarction; other abbreviations as in Table 1 
Table 3 Cardiac Magnetic Resonance Imaging Outcomes in Study Population

\begin{tabular}{|c|c|c|c|c|c|c|}
\hline & $\begin{array}{l}\text { Scan } 1 \\
\text { (48 Hours) }\end{array}$ & & & $\begin{array}{l}\text { Scan } 2 \\
\text { (6 Months) }\end{array}$ & & \\
\hline & NTA & TA & p Value & NTA & TA & $\mathrm{p}$ Value \\
\hline IS T2, ms & $57.9 \pm 7.9$ & $52.1 \pm 6.3$ & 0.022 & $39.5 \pm 3.0$ & $40.6 \pm 2.8$ & 0.517 \\
\hline $\mathrm{RS} T 2, \mathrm{~ms}$ & $41.9 \pm 2.7$ & $42.4 \pm 2.8$ & 0.552 & $39.1 \pm 2.9$ & $39.6 \pm 2.7$ & 0.612 \\
\hline IS EDWT, mm & $11.4 \pm 2.2$ & $9.3 \pm 1.6$ & 0.013 & $4.0 \pm 1.1$ & $5.7 \pm 1.0$ & 0.008 \\
\hline RS EDWT, mm & $7.0 \pm 1.4$ & $6.9 \pm 1.3$ & 0.883 & $8.3 \pm 1.3$ & $7.8 \pm 1.2$ & 0.443 \\
\hline IS T2*, ms & $29.3 \pm 9.4$ & $37.8 \pm 7.0$ & 0.007 & $33.9 \pm 4.9$ & $35.7 \pm 5.7$ & 0.435 \\
\hline $\mathrm{RS} \mathrm{T2*}$, ms & $37.1 \pm 3.4$ & $38.0 \pm 3.1$ & 0.662 & $38.0 \pm 3.7$ & $38.2 \pm 4.4$ & 0.712 \\
\hline Hemorrhage, \% of myocardium & $11.6 \pm 6.8$ & $7.1 \pm 3.8$ & 0.02 & - & - & - \\
\hline Hemorrhage, n (\%) & $13(52.0)$ & $7(20.0)$ & 0.02 & - & - & - \\
\hline MVO, \% of myocardium & $6.7 \pm 4.2$ & $3.4+3.1$ & 0.003 & - & - & - \\
\hline MVO, n (\%) & $22(88.0)$ & $19(54.3)$ & 0.013 & - & - & - \\
\hline Infarct Size, $\%$ of myocardium & $27.3 \pm 9.1$ & $19.8 \pm 8.2$ & 0.001 & $16.8 \pm 8.7$ & $13.8 \pm 4.8$ & 0.022 \\
\hline LVEDVI, $\mathrm{ml} / \mathrm{mm} 2$ & $68.6 \pm 17.6$ & $70.4 \pm 11.9$ & 0.717 & $91.9 \pm 21.1$ & $68.3 \pm 8.7$ & 0.013 \\
\hline LVESVI, ml/mm2 & $37.1 \pm 12.3$ & $38.1 \pm 9.9$ & 0.873 & $52.1 \pm 16.9$ & $32.4 \pm 5.3$ & 0.008 \\
\hline LVSVI, ml/mm2 & $30.4 \pm 9.5$ & $32.7 \pm 4.3$ & 0.546 & $40.4 \pm 11.2$ & $35.8 \pm 8.1$ & 0.301 \\
\hline LVEF, \% & $44.7 \pm 8.1$ & $46.4 \pm 5.9$ & 0.392 & $46.8 \pm 10.5$ & $53.8 \pm 7.7$ & 0.11 \\
\hline IS-SWT, \% & $4.9 \pm 24.8$ & $-2.9 \pm 18.3$ & 0.224 & $3.5 \pm 19.5$ & $74.8 \pm 58.5$ & 0.003 \\
\hline
\end{tabular}

Abbreviations. EDWT end diastolic wall thickness; IS infarct segment; IS-SWT infarct segment systolic wall thickening; LVEDVI left ventricular end-diastolic volume index; LVEF left ventricular ejection fraction; LVESVI left ventricular end-systolic volume index; LVSVI left ventricular stroke volume index; MVO microvascular obstruction; RS remote segment; other abbreviations as in Tables 1 and 2

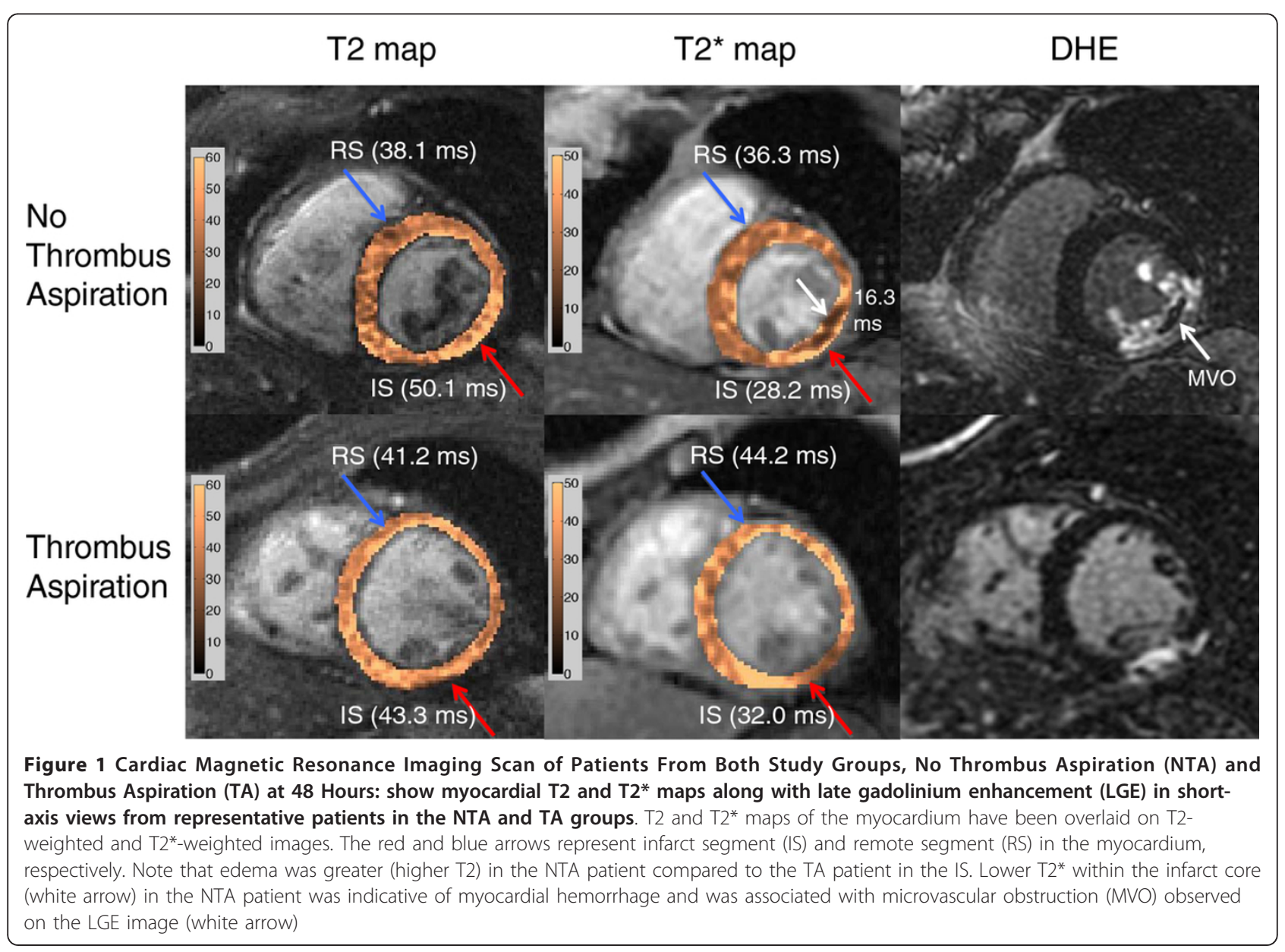




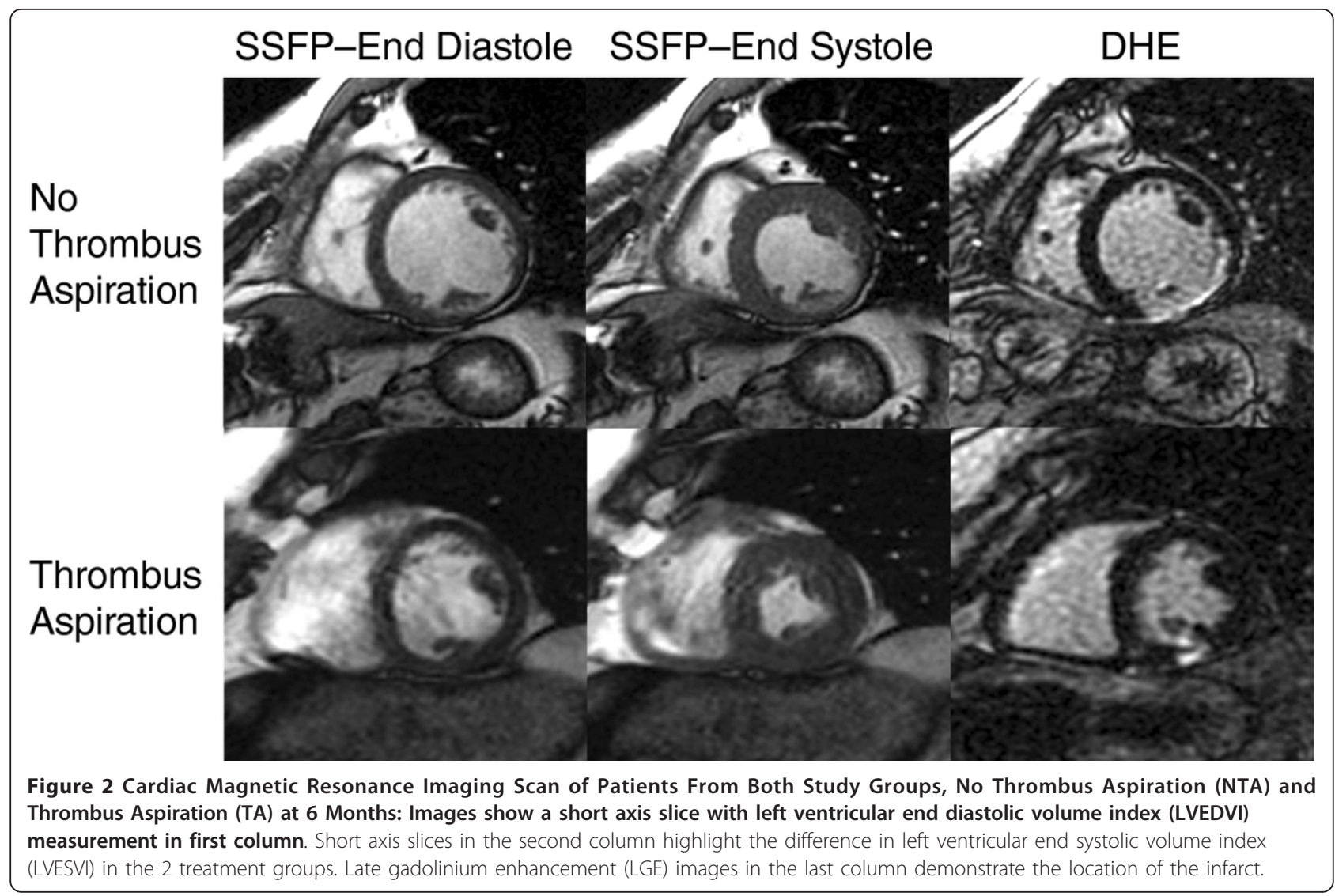

reduced myocardial edema and hemorrhage in the acute phase. This is the first study to use quantitative CMR parameters to evaluate the effects of TA on myocardial edema and myocardial hemorrhage. Recently, the utility of quantitative CMR in the longitudinal evaluation of myocardial edema, hemorrhage, and MVO has been demonstrated in preclinical models of acute myocardial infarction [31].

Both myocardial hemorrhage and MVO have been extensively linked to worse clinical outcome post acute myocardial infarction $[22,24,33,34]$. Recently, the EXPIRA trial [17] had shown that thrombectomy reduced the extent of MVO and infarct size after acute myocardial infarction, which is consistent with our findings. Our study had an even higher incidence of MVO in the NTA group compared to the EXPIRA trial $(88 \%$ vs. $72.9 \%$ ); however, the absolute difference between the 2 treatment groups was similar in both studies $(34 \%$ vs. $41.4 \%)$.

Myocardial hemorrhage is considered to be a sign of severe microvascular injury [35]. Histologically, it is characterized by vascular cell damage, with leakage of red blood cells from injured cells affecting mainly the mid-myocardial layer [36]. It is a frequent complication after successful myocardial reperfusion, affecting $25 \%$ of patients, and is an independent predictor of adverse left ventricular remodeling regardless of the initial infarct size, and a marker of late arrhythmic risk $[22,31,34]$. The pathophysiology relating MVO and myocardial hemorrhage is unclear. It is possible that MVO leads to endothelial damage and subsequent extravasation of erythrocytes to the interstitium. However, it has also been postulated that the myocardial hemorrhage causes swelling of the myocardium and subsequent compression of the microvasculature, thereby actually causing or worsening MVO [37,38]. While the mechanism is uncertain, the fact that TA is associated with a lower incidence of $\mathrm{MVO}$ and reduced $\mathrm{T} 2 *$ indicating reduced myocardial hemorrhage points to the utility of this adjunctive therapy in primary PCI. Mechanical thrombus removal may explain the better results obtained in the TA group.

Extensive preclinical and human studies have established that T2 signal hyperintensity by CMR indicates increased myocardial water content $[39,40]$. T2 may increase within 30 minutes of ischemia onset, even before detectable injury by troponin or late gadolinium enhancement $[41,42]$. Also, end-diastolic wall thickness has been shown to be able to identify and monitor the presence, extent and resolution of myocardial edema following primary PCI $[43,44]$. The presence of myocardial 
edema after an acute coronary syndrome has been recently shown to be associated with a higher hazard of cardiovascular event or death within 6 months [45]. Hence, our observation that TA during primary PCI is associated with reduced myocardial edema has important clinical implications and can explain why 2 previous randomized clinical trials have shown a reduction in major adverse cardiac events in the thrombectomy group $[17,21]$.

We used a quantitative T2 mapping technique to delineate the extent of myocardial edema instead of a T2-weighted imaging approach. T2-weighted imaging techniques have known limitations, which impairs their validity $[39,46]$. Some of these limitations include: a) surface coil intensity inhomogeneity leading to variability in myocardial signal, b) sub-endocardial bright signal artifact caused by stagnant blood, c) cardiac motion leading to reduced myocardial signal, d) subjective nature of qualitative T2-weighted imaging assessment which then poses significant challenges in tracking longitudinal changes in a robust manner. Recently other studies have demonstrated that quantitative T2 mapping addresses the known problems associated with $\mathrm{T} 2$ weighted imaging and can offer increased accuracy in the detection of myocardial edema [31,47-50].

Hemorrhage is known to not only reduce $\mathrm{T} 2 *$ values but also T2 relaxation times [50]. An unexpected finding in our study is that patents in the NTA group had increased $\mathrm{T} 2$ relaxation times despite having more hemorrhage. We postulate that patients in the NTA group had more hemorrhage, more extensive myocardial injury and therefore more edema. The fact that end-diastolic wall thickness was increased acutely in the infarct segment of the NTA group supports our hypothesis that these patients indeed have more edema. In fact, we may have obtained an even higher T2 value in NTA patients if susceptibility effects of hemorrhage were not present.

In contrast to the EXPIRA [17] trial that had CMR follow up at 3 months, we assessed left ventricular remodeling at 6 months when infarct expansion is well established. Using left ventricular remodeling parameters indexed to body surface area we were able to demonstrate a significant improvement in LVEDVI, LVESVI and infarct segment systolic wall thickening in the TA group. Two prior studies using echocardiography have had conflicting results with respect to left ventricular remodeling and use of TA. De Luca and colleagues showed that in 76 patients with anterior myocardial infarction, TA was associated with significantly lower end-diastolic and end-systolic left ventricular volumes on transthoracic echocardiography at 6 months compared to conventional primary PCI [11]. In contrast, Galiuto et al. showed no significant difference in left ventricular volumes at 6 months with thrombectomy using myocardial contrast echocardiography [51]. Our significant findings in all types of infarcts, can perhaps be explained by the superiority of CMR over conventional echocardiography and myocardial contrast echocardiography in terms of spatial resolution and endocardial definition [52]. In addition, we were able to demonstrate that TA is associated with reduced myocardial hemorrhage, which in turn is an independent predictor of adverse left ventricular remodeling [34].

In accordance with the literature, TA also improved final myocardial blush grade and the rate of ST-segment resolution post primary PCI $[11,17,18,20]$. The degree of improvement in both these parameters of microvascular integrity was comparable to previous studies.

\section{Study limitations}

This study represents a single-centre non-randomized experience with a limited number of patients. However, baseline demographic and angiographic characteristics appear to be well matched in our 2 study groups. In particular, time to reperfusion, culprit vessel distribution, thrombus burden, enzymatic infarct size and adjunctive glycoprotein IIb/IIIa inhibitor use were similar in both groups. The sample size is similar to published CMR studies that have investigated myocardial edema, myocardial hemorrhage and MVO in other clinical settings. TA use was left to operator discretion, which can lead to a selection bias that may impact outcomes. However, the lack of a trend towards a higher thrombus burden in the TA group suggests that most of the TA use was based on a routine use policy. Lastly, we used a surface coil which can decrease the sensitivity for detecting inferolateral edema and infarction with an opposite effect in the anteroseptal region, due to an inhomogeneous coil sensitivity profile.

\section{Conclusions}

TA as an adjunctive therapy to primary PCI is associated with a reduction in the degree of myocardial edema, myocardial hemorrhage, infarct size, left ventricular remodeling, and MVO after STEMI. The positive impact of TA on myocardial edema, myocardial hemorrhage and left ventricular remodeling using CMR is a novel finding and therefore, we believe our data contribute important findings to the current literature on this topic. However, given the small sample size and nonrandomized design the results of our study are hypothesis generating only and one cannot draw a causal relationship between favorable outcomes and use of TA in primary PCI. The results of large randomized trials to assess the utility of TA on the amount of salvaged myocardium using CMR are pending [53,54]. 


\section{Abbreviations}

CMR: Cardiovascular magnetic resonance; LVEDVI: Left ventricular end diastolic volume index; LVESVI: Left ventricular end systolic volume index; LVSVI: Left ventricular stroke volume index; MVO: Microvascular obstruction; NTA: No thrombus aspiration; PCl: Percutaneous coronary intervention; STEMI: ST-segment elevation myocardial infarction; TA: Thrombus aspiration; TIMI: Thrombolysis in myocardial infarction

\section{Acknowledgements}

The authors would like to thank Malaika Mohammed, B.A.S. and Rhonda Walcarius, M.R.T. (MR) M.R.T.(R) BSc. for their assistance in patient recruitment and scanning.

Dr. Connelly is supported by a Heart and Stroke Foundation of Canada Phase 1 Clinician Scientist Award. Dr. Dick is supported by the Heart and Stroke Foundation of Canada. This work was supported in part by a Canadian Institutes of Health Research (ClHR) operating grant and the Ontario Research Fund.

\section{Authors' contributions}

MIZ: Study design, patient identification, analysis and interpretation of data, statistics, drafting of the manuscript. NRG: Study design, analysis and interpretation of data, statistics, drafting of the manuscript. KAC: Study design, analysis and interpretation of data, statistics, revising the manuscript critically for important intellectual content. SBJ: Patient identification, analysis and interpretation of data, statistics, revising the manuscript critically for important intellectual content. BHS: Analysis and interpretation of data, revising the manuscript critically for important intellectual content. EAC Analysis and interpretation of data, revising the manuscript critically for important intellectual content. GAW: Study design, analysis and interpretation of data, statistics, revising the manuscript critically for important intellectual content. AJD: Study design, analysis and interpretation of data, statistics, revising the manuscript critically for important intellectual content. All authors have read and approved the final manuscript.

\section{Competing interests}

Dr. Wright receives research funding from GE Healthcare.

Received: 13 September 2011 Accepted: 26 March 2012 Published: 26 March 2012

\section{References}

1. Keeley EC, Boura JA, Grines CL. Primary angioplasty versus intravenous thrombolytic therapy for acute myocardial infarction: a quantitative review of 23 randomised trials. Lancet. 2003;361:13-20. doi:10.1016/S0140-6736(03) 12113-7.

2. Chan MY, Sun JL, Newby LK, Shaw LK, Lin M, Peterson ED, Califf RM, Kong DF, Roe MT. Long-term mortality of patients undergoing cardiac catheterization for ST-elevation and non-ST-elevation myocardial infarction. Circulation. 2009;119:3110-7. doi:10.1161/CIRCULATIONAHA.108.799981.

3. Jaffe $R$, Charron T, Puley G, Dick A, Strauss BH. Microvascular obstruction and the no-reflow phenomenon after percutaneous coronary intervention. Circulation. 2008;117:3152-6. doi:10.1161/CIRCULATIONAHA.107.742312.

4. Jaffe R, Dick A, Strauss BH. Prevention and treatment of microvascular obstruction-related myocardial injury and coronary no-reflow following percutaneous coronary intervention: a systematic approach. JACC Cardiovasc Interv. 2010;3:695-704. doi:10.1016/j.jcin.2010.05.004.

5. Niccoli G, Burzotta F, Galiuto L, Crea F. Myocardial no-reflow in humans. J Am Coll Cardiol. 2009;54:281-92. doi:10.1016/j.jacc.2009.03.054.

6. Rezkalla SH, Kloner RA. No-reflow phenomenon. Circulation. 2002;105:656-62. doi:10.1161/hc0502.102867.

7. Ali A, Cox D, Dib N, Brodie B, Berman D, Gupta N, Browne K, Iwaoka R, Azrin M, Stapleton D, Setum C, Popma J. Rheolytic thrombectomy with percutaneous coronary intervention for infarct size reduction in acute myocardial infarction: 30-day results from a multicenter randomized study. J Am Coll Cardiol. 2006:48:244-52. doi:10.1016/j.jacc.2006.03.044.

8. Antoniucci D, Valenti R, Migliorini A, Parodi G, Memisha G, Santoro GM, Sciagra R. Comparison of rheolytic thrombectomy before direct infarct artery stenting versus direct stenting alone in patients undergoing percutaneous coronary intervention for acute myocardial infarction. Am J Cardiol. 2004;93:1033-5. doi:10.1016/j.amjcard.2004.01.011.
9. Burzotta F, Trani C, Romagnoli E, Mazzari MA, Rebuzzi AG, De VM, Garramone B, Giannico F, Niccoli G, Biondi-Zoccai GG, Schiavoni G, Mongiardo R, Crea F. Manual thrombus-aspiration improves myocardial reperfusion: the randomized evaluation of the effect of mechanical reduction of distal embolization by thrombus-aspiration in primary and rescue angioplasty (REMEDIA) trial. J Am Coll Cardiol. 2005;46:371-6. doi:10.1016/j.jacc.2005.04.057.

10. Chevalier B, Gilard M, Lang I, Commeau P, Roosen J, Hanssen M, Lefevre T, Carrie D, Bartorelli A, Montalescot G, Parikh K. Systematic primary aspiration in acute myocardial percutaneous intervention: a multicentre randomised controlled trial of the export aspiration catheter. Eurolntervention. 2008:4:222-8. doi:10.4244/EIJV4I2A40.

11. De LL, Sardella G, Davidson CJ, De PG, Beraldi M, Tommasone T, Mancone M, Nguyen BL, Agati L, Gheorghiade M, Fedele F. Impact of intracoronary aspiration thrombectomy during primary angioplasty on left ventricular remodelling in patients with anterior ST elevation myocardial infarction. Heart. 2006;92:951-7. doi:10.1136/hrt.2005.074716.

12. Javaid A, Siddiqi NH, Steinberg $D H$, Buch AN, Slottow TL, Roy $P$, Sammee $S$, Okabe T, Suddath WO, Kent KM, Satler LF, Pichard AD, Smith K, Xue Z, Lindsay J Jr, Waksman R. Adjunct thrombus aspiration reduces mortality in patients undergoing percutaneous coronary intervention for ST-elevation myocardial infarction with high-risk angiographic characteristics. Am J Cardiol. 2008;101:452-6. doi:10.1016/j.amjcard.2007.09.091.

13. Kaltoft A, Bottcher M, Nielsen SS, Hansen HH, Terkelsen C, Maeng M, Kristensen J, Thuesen L, Krusell LR, Kristensen SD, Andersen HR, Lassen JF, Rasmussen K, Rehling M, Nielsen T, Botker HE. Routine thrombectomy in percutaneous coronary intervention for acute ST-segment-elevation myocardial infarction: a randomized, controlled trial. Circulation. 2006;114:40-7. doi:10.1161/CIRCULATIONAHA.105.595660.

14. Lanjewar C, Jolly S, Mehta SR. Effects of aspiration thrombectomy on mortality in patients with acute myocardial infarction undergoing primary percutaneous coronary intervention: a meta-analysis of the randomized trials. Indian Heart J. 2009;61:335-40.

15. Lefevre T, Garcia E, Reimers B, Lang I, di MC, Colombo A, Neumann FJ, Chavarri MV, Brunel P, Grube E, Thomas M, Glatt B, Ludwig J. X-sizer for thrombectomy in acute myocardial infarction improves ST-segment resolution: results of the $\mathrm{X}$-sizer in $\mathrm{AMI}$ for negligible embolization and optimal ST resolution (X AMINE ST) trial. J Am Coll Cardiol. 2005;46:246-52. doi:10.1016/j.jacc.2005.04.031.

16. Napodano M, Pasquetto G, Sacca S, Cernetti C, Scarabeo V, Pascotto P, Reimers B. Intracoronary thrombectomy improves myocardial reperfusion in patients undergoing direct angioplasty for acute myocardial infarction. J Am Coll Cardiol. 2003;42:1395-402. doi:10.1016/S0735-1097(03)01041-6.

17. Sardella G, Mancone M, Bucciarelli-Ducci C, Agati L, Scardala R, Carbone I, Francone M, Di RA, Benedetti G, Conti G, Fedele F. Thrombus aspiration during primary percutaneous coronary intervention improves myocardial reperfusion and reduces infarct size: the EXPIRA (thrombectomy with export catheter in infarct-related artery during primary percutaneous coronary intervention) prospective, randomized trial. J Am Coll Cardiol. 2009;53:309-15. doi:10.1016/j.jacc.2008.10.017.

18. Silva-Orrego P, Colombo P, Bigi R, Gregori D, Delgado A, Salvade $P$, Oreglia J, Orrico P, de BA, Piccalo G, Bossi I, Klugmann S. Thrombus aspiration before primary angioplasty improves myocardial reperfusion in acute myocardial infarction: the DEAR-MI (Dethrombosis to Enhance Acute Reperfusion in Myocardial Infarction) study. J Am Coll Cardiol. 2006,48:1552-9.

19. Stone GW, Webb J, Cox DA, Brodie BR, Qureshi M, Kalynych A, Turco M, Schultheiss HP, Dulas D, Rutherford BD, Antoniucci D, Krucoff MW, Gibbons RJ, Jones D, Lansky AJ, Mehran R. Distal microcirculatory protection during percutaneous coronary intervention in acute ST-segment elevation myocardial infarction: a randomized controlled trial. JAMA. 2005;293:1063-72. doi:10.1001/jama.293.9.1063.

20. Svilaas T, Vlaar PJ, van der Horst IC, Diercks GF, de Smet BJ, van den Heuvel AF, Anthonio RL, Jessurun GA, Tan ES, Suurmeijer AJ, Zijlstra F. Thrombus aspiration during primary percutaneous coronary intervention. N Engl J Med. 2008;358:557-67. doi:10.1056/NEJMoa0706416.

21. Vlaar PJ, Svilaas T, van der Horst IC, Diercks GF, Fokkema ML, de Smet BJ, van den Heuvel AF, Anthonio RL, Jessurun GA, Tan ES, Suurmeijer AJ, Zijlstra F. Cardiac death and reinfarction after 1 year in the Thrombus Aspiration during Percutaneous coronary intervention in Acute myocardial 
infarction Study (TAPAS): a 1-year follow-up study. Lancet. 2008:371:1915-20. doi:10.1016/50140-6736(08)60833-8.

22. Ganame J, Messalli G, Dymarkowski S, Rademakers FE, Desmet W, Van de WF, Bogaert J. Impact of myocardial haemorrhage on left ventricular function and remodelling in patients with reperfused acute myocardial infarction. Eur Heart J. 2009;30:1440-9. doi:10.1093/eurheartj/ehp093.

23. Hombach V, Merkle N, Bernhard P, Rasche V, Rottbauer W. Prognostic significance of cardiac magnetic resonance imaging: Update 2010. Cardiol J. 2010;17:549-57.

24. Wu KC, Zerhouni EA, Judd RM, Lugo-Olivieri CH, Barouch LA, Schulman SP, Blumenthal RS, Lima JA. Prognostic significance of microvascular obstruction by magnetic resonance imaging in patients with acute myocardial infarction. Circulation. 1998;97:765-72.

25. Antman EM, Anbe DT, Armstrong PW, Bates ER, Green LA, Hand M, Hochman JS, Krumholz HM, Kushner FG, Lamas GA, Mullany CJ, Ornato JP, Pearle DL, Sloan MA, Smith SC Jr, Alpert JS, Anderson JL, Faxon DP, Fuster V, Gibbons RJ, Gregoratos G, Halperin JL, Hiratzka LF, Hunt SA, Jacobs AK, Ornato JP. ACC/AHA guidelines for the management of patients with ST-elevation myocardial infarction; A report of the American College of Cardiology/American Heart Association Task Force on Practice Guidelines (Committee to Revise the 1999 Guidelines for the Management of patients with acute myocardial infarction). J Am Coll Cardiol. 2004;44:E1-E211. doi:10.1016/j.jacc.2004.07.014

26. The Thrombolysis in Myocardial Infarction (TIMI) trial. Phase I findings. TIMI Study Group. N Engl J Med. 1985;312:932-6.

27. Early effects of tissue-type plasminogen activator added to conventional therapy on the culprit coronary lesion in patients presenting with ischemic cardiac pain at rest. Results of the Thrombolysis in Myocardial Ischemia (TIMI IIIA) Trial. Circulation. 1993;87:38-52.

28. van 't Hof AW, Liem A, Suryapranata H, Hoorntje JC, de Boer MJ, Zijstra F. Angiographic assessment of myocardial reperfusion in patients treated with primary angioplasty for acute myocardial infarction: myocardial blush grade. Zwolle Myocardial Infarction Study Group. Circulation. 1998;97:2302-6.

29. van 't Hof AW, Liem A, de Boer MJ, Zijlstra F. Clinical value of 12-lead electrocardiogram after successful reperfusion therapy for acute myocardial infarction. Zwolle Myocardial infarction Study Group. Lancet. 1997;350:615-9. doi:10.1016/50140-6736(96)07120-6.

30. Foltz WD, Al-Kwifi O, Sussman MS, Stainsby JA, Wright GA. Optimized spiral imaging for measurement of myocardial T2 relaxation. Magn Reson Med. 2003:49:1089-97. doi:10.1002/mrm.10467.

31. Ghugre NR, Ramanan V, Pop M, Yang Y, Barry J, Qiang B, Connelly KA, Dick AJ, Wright GA. Quantitative tracking of edema, hemorrhage, and microvascular obstruction in subacute myocardial infarction in a porcine model by MRI. Magn Reson Med. 2011;66:1129-41. doi:10.1002/mrm.22855.

32. Schmidt A, Azevedo CF, Cheng A, Gupta SN, Bluemke DA, Foo TK, Gerstenblith G, Weiss RG, Marban E, Tomaselli GF, Lima JA, Wu KC. Infarct tissue heterogeneity by magnetic resonance imaging identifies enhanced cardiac arrhythmia susceptibility in patients with left ventricular dysfunction. Circulation. 2007;115:2006-14. doi:10.1161/CIRCULATIONAHA. 106.653568

33. Cochet AA, Lorgis L, Lalande A, Zeller M, Beer JC, Walker PM, Touzery C, Wolf JE, Brunotte F, Cottin Y. Major prognostic impact of persistent microvascular obstruction as assessed by contrast-enhanced cardiac magnetic resonance in reperfused acute myocardial infarction. Eur Radiol. 2009:19:2117-26. doi:10.1007/s00330-009-1395-5.

34. Mather AN, Fairbairn TA, Ball SG, Greenwood JP, Plein S. Reperfusion haemorrhage as determined by cardiovascular MRI is a predictor of adverse left ventricular remodelling and markers of late arrhythmic risk. Heart. 2011;97:453-9. doi:10.1136/hrt.2010.202028.

35. Piper HM, Garcia-Dorado D, Ovize M. A fresh look at reperfusion injury. Cardiovasc Res. 1998;38:291-300. doi:10.1016/S0008-6363(98)00033-9.

36. Garcia-Dorado D, Theroux P, Solares J, Alonso J, Fernandez-Aviles F, Elizaga J, Soriano J, Botas J, Munoz R. Determinants of hemorrhagic infarcts. Histologic observations from experiments involving coronary occlusion, coronary reperfusion, and reocclusion. Am J Pathol. 1990;137:301-11.

37. Dirksen MT, Laarman GJ, Simoons ML, Duncker DJ. Reperfusion injury in humans: a review of clinical trials on reperfusion injury inhibitory strategies. Cardiovasc Res. 2007:74:343-55. doi:10.1016/..cardiores.2007.01.014.

38. Yellon DM, Hausenloy DJ. Myocardial reperfusion injury. N Engl J Med. 2007;357:1121-35. doi:10.1056/NEJMra071667.
39. Abdel-Aty H, Simonetti O, Friedrich MG. T2-weighted cardiovascular magnetic resonance imaging. J Magn Reson Imaging. 2007;26:452-9. doi:10.1002/jmri.21028.

40. Aletras AH, Tilak GS, Natanzon A, Hsu LY, Gonzalez FM, Hoyt RF Jr, Arai AE. Retrospective determination of the area at risk for reperfused acute myocardial infarction with T2-weighted cardiac magnetic resonance imaging: histopathological and displacement encoding with stimulated echoes (DENSE) functional validations. Circulation. 2006;113:1865-70. doi:10.1161/CIRCULATIONAHA.105.576025.

41. Abdel-Aty H, Cocker M, Meek C, Tyberg JV, Friedrich MG. Edema as a very early marker for acute myocardial ischemia: a cardiovascular magnetic resonance study. J Am Coll Cardiol. 2009;53:1194-201. doi:10.1016/j. jacc.2008.10.065.

42. Nilsson JC, Nielsen G, Groenning BA, Fritz-Hansen T, Sondergaard L, Jensen $G B$, Larsson HB. Sustained postinfarction myocardial oedema in humans visualised by magnetic resonance imaging. Heart. 2001;85:639-42. doi:10.1136/heart.85.6.639.

43. Merli E, Sutherland GR, Bijnens B, Fischer A, Chaparro M, Karu T, Sutcliffe S, Marciniak A, Baltabaeva A, Bunce N, Brecker S. Usefulness of changes in left ventricular wall thickness to predict full or partial pressure reperfusion in STelevation acute myocardial infarction. Am J Cardiol. 2008;102:249-56. doi:10.1016/j.amjcard.2008.03.047.

44. Turschner O, D'hooge J, Dommke C, Claus P, Verbeken E, De S, Bijnens B, Sutherland GR. The sequential changes in myocardial thickness and thickening which occur during acute transmural infarction, infarct reperfusion and the resultant expression of reperfusion injury. Eur Heart J. 2004:25:794-803. doi:10.1016/.jehj.2004.01.006.

45. Raman SV, Simonetti OP, Winner MW, Dickerson JA, He X, Mazzaferri EL Jr, Ambrosio G. Cardiac magnetic resonance with edema imaging identifies myocardium at risk and predicts worse outcome in patients with non-STsegment elevation acute coronary syndrome. J Am Coll Cardiol. 2010;55:2480-8. doi:10.1016/j.jacc.2010.01.047.

46. Arai $A E$. Using magnetic resonance imaging to characterize recent myocardial injury: utility in acute coronary syndrome and other clinical scenarios. Circulation. 2008;118:795-6. doi:10.1161/ CIRCULATIONAHA.108.797373.

47. Dall'Armellina E, Karia N, Lindsay AC, Karamitsos TD, Ferreira V, Robson MD, Kellman P, Francis JM, Forfar C, Prendergast BD, Banning AP, Channon KM, Kharbanda RK, Neubauer S, Choudhury RP. Dynamic changes of edema and late gadolinium enhancement after acute myocardial infarction and their relationship to functional recovery and salvage index. Circ Cardiovasc Imaging. 2011:4:228-36. doi:10.1161/CIRCIMAGING.111.963421.

48. Giri S, Chung YC, Merchant A, Mihai G, Rajagopalan S, Raman SV, Simonetti OP. T2 quantification for improved detection of myocardial edema. J Cardiovasc Magn Reson. 2009;11:56. doi:10.1186/1532-429X-11-56.

49. Mather AN, Fairbairn TA, Artis NJ, Greenwood JP, Plein S. Timing of cardiovascular MR imaging after acute myocardial infarction: effect on estimates of infarct characteristics and prediction of late ventricular remodeling. Radiology. 2011;261:116-26. doi:10.1148/radiol.11110228.

50. Verhaert D, Thavendiranathan P, Giri S, Mihai G, Rajagopalan S, Simonetti OP, Raman SV. Direct T2 quantification of myocardial edema in acute ischemic injury. JACC Cardiovasc Imaging. 2011;4:269-78. doi:10.1016/ j.jcmg.2010.09.023.

51. Galiuto L, Garramone B, Burzotta F, Lombardo A, Barchetta S, Rebuzzi AG, Crea F. Thrombus aspiration reduces microvascular obstruction after primary coronary intervention: a myocardial contrast echocardiography substudy of the REMEDIA Trial. J Am Coll Cardiol. 2006;48:1355-60. doi:10.1016/j.jacc.2006.05.059.

52. Grothues F, Smith GC, Moon JC, Bellenger NG, Collins P, Klein HU, Pennell DJ. Comparison of interstudy reproducibility of cardiovascular magnetic resonance with two-dimensional echocardiography in normal subjects and in patients with heart failure or left ventricular hypertrophy. Am J Cardiol. 2002;90:29-34. doi:10.1016/S0002-9149(02)02381-0.

53. Frobert O, Lagerqvist B, Gudnason T, Thuesen L, Svensson R, Olivecrona GK, James SK. Thrombus Aspiration in ST-Elevation myocardial infarction in Scandinavia (TASTE trial). A multicenter, prospective, randomized, controlled clinical registry trial based on the Swedish angiography and angioplasty registry (SCAAR) platform. Study design and rationale. Am Heart J. 2010;160:1042-8. doi:10.1016/j.ahj.2010.08.040. 
54. Gibson CM, Maehara A, Lansky AJ, Wohrle J, Stuckey T, Dave R, Cox D, Grines C, Dudek D, Steg G, Parise H, Wolff SD, Cristea E, Stone GW. Rationale and design of the INFUSE-AMI study: A $2 \times 2$ factorial, randomized, multicenter, single-blind evaluation of intracoronary abciximab infusion and aspiration thrombectomy in patients undergoing percutaneous coronary intervention for anterior ST-segment elevation myocardial infarction. Am Heart J. 2011;161:478-86. doi:10.1016/j. ahj.2010.10.006.

doi:10.1186/1532-429X-14-19

Cite this article as: Zia et al:: Thrombus aspiration during primary percutaneous coronary intervention is associated with reduced myocardial edema, hemorrhage, microvascular obstruction and left ventricular remodeling. Journal of Cardiovascular Magnetic Resonance 2012 14:19.

Submit your next manuscript to BioMed Central and take full advantage of:

- Convenient online submission

- Thorough peer review

- No space constraints or color figure charges

- Immediate publication on acceptance

- Inclusion in PubMed, CAS, Scopus and Google Scholar

- Research which is freely available for redistribution

Submit your manuscript at www.biomedcentral.com/submit
() Biomed Central 